\title{
Setting biodiversity goals
}

A new biodiversity decade is about to start and hopefully will achieve just progress for both people and the planet.

n October 2010, the Convention on Biological Diversity (CBD) signed up to a promising 10-year framework, the Strategic Plan for Biodiversity 2011-2020, which represented a major step to ensure that by 2050 biodiversity would be 'valued, conserved, restored and wisely used' in a world where people live in harmony with nature, according to the vision stated in the strategic plan. Underpinning the plan were the so-called 20 Aichi targets aiming to articulate the specific areas of intervention to achieve a set of broad strategic goals addressing the causes of biodiversity loss and promoting its sustainable use, safeguarding ecosystems, ensuring all would benefit from biodiversity and promoting implementation through participatory planning. The CBD referred to the targets as ambitious but achievable. A decade later, in October 2020, signatories to the CBD were due to discuss progress towards the Aichi targets at the fifteenth Conference of the Parties (COP 15) in Kunming, China, but the meeting was postponed until May 2021 due to the impacts of the COVID-19 pandemic. In the lead up to the meeting, research efforts and wider debates about the Aichi targets have intensified and have all sent a strong and unequivocal message: the state of biodiversity is now worrying more than ever; the Aichi targets have largely not been met. What went wrong? Some feel the problem lays with the ever-lasting challenge of measuring living nature, others refer to inadequate national implementation strategies. Answering the question for CBD members is of critical importance. As COP 15 to the CBD is also the gathering where the parties will agree on a post-2020 biodiversity framework, it is crucial for them to learn from past mistakes. Indeed, the parties have been working to define a new framework and a new set of targets, this time for 2030. Back in October, in preparation for the COP, a revised draft of the new set of biodiversity targets was released. Waiting for the final deliberations in China, some experts have already raised concerns about the effectiveness of the proposed new framework. More specifically, some point to the lack of recognition of the role of agro-ecosystems in conservation, reflecting on the challenges of protecting more land in regions under pressure to feed a growing population (for example, Sub-Saharan Africa). Aichi target 11 required that by 2020 at least $17 \%$ of terrestrial areas and $10 \%$ of

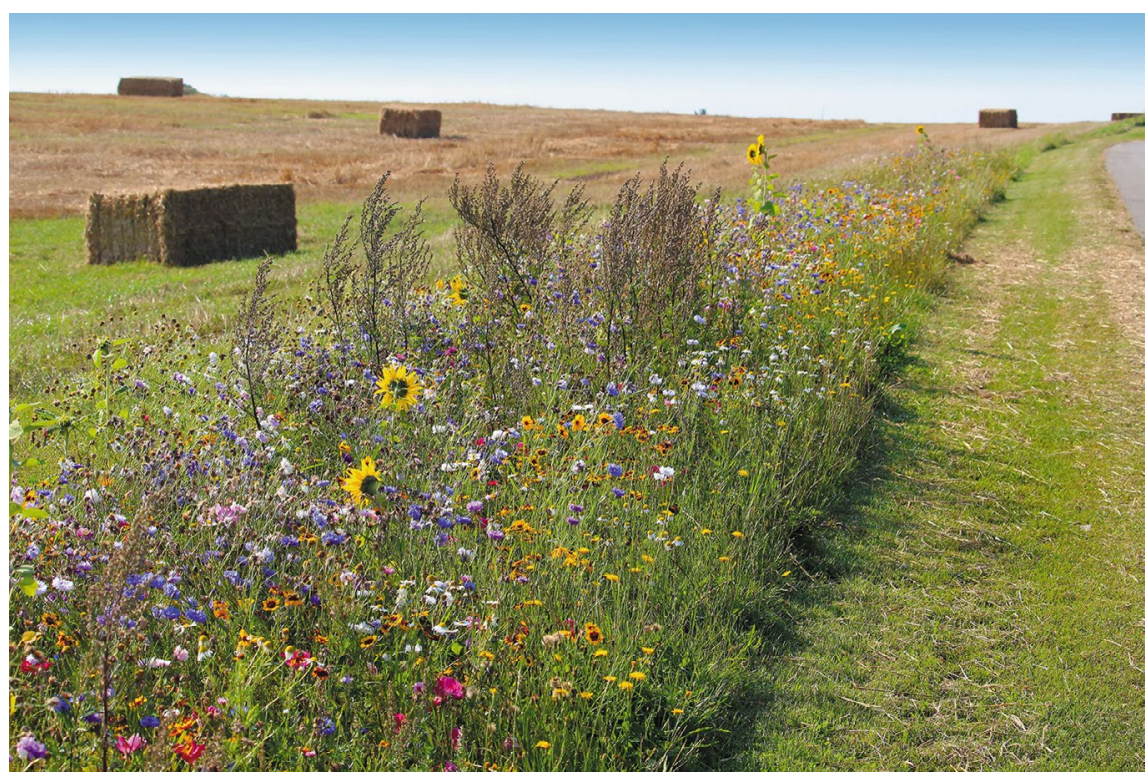

Credit: Ines Porada / Alamy Stock Photo

marine areas across the world, especially those of critical importance for biodiversity, should be conserved and equitably managed. Alarmed by lack of progress towards the target, prominent conservationists proposed to ramp up the ambition and protect half of the Earth's surface to halt biodiversity decline. A study by Mehrabi and colleagues assessed the food production costs of the proposal and found that globally about $23-25 \%$ of non-food calories and 3-29\% of food calories could be lost. Another study by Schleicher and co-authors found that in the event of including all ecoregions in the proposal there would be substantial socio-economic impacts as over one billion people currently live in areas that would be protected under Half Earth. Both articles, part of a joint collection with Nature Ecology \& Evolution, shed light on the challenges of reconciling development needs with biodiversity protection. Some possible solutions to this challenge are controversial; for example, biodiversity offsetting, which refers to actions intended to deliver biodiversity gains as a way of compensating for development impacts. In another study in the collection, Damiens et al. analysed policy documents produced between 1958 and 2019 and showed that biodiversity offsetting was historically promoted through approaches encouraging economic growth with no consideration of biocultural limits. They showed also that, recently, more transformative approaches include offsetting as a tool to transition towards economic systems respectful of planetary boundaries, but their success hinges on realizing quite challenging governance changes.

Realizing the CBD vision by 2050 requires acknowledging the need of transformative change. What does it mean in practice? It means understanding as best we can the complexity of human-nature interactions. But it also means accepting that there is a lot we don't know and most probably won't have enough time to know if we don't act now. Against this backdrop, the biodiversity community can influence the debate about what should happen in order to sustainably manage living nature. How? Perhaps, as Wyborn and colleagues suggest in their paper, also part of the collection, they could use some imagination to visualize how the future will unfold from the choices made today. There are multiple possible paths to set the world on course to live in harmony with nature - none is perfect, all are possible. This variety reflects diverse values and relations with biodiversity that in turn drive choices. Rather than shying away from it, the biodiversity community should embrace the challenge fully in order to define new priorities for both research and action.

Published online: 4 March 2021 https://doi.org/10.1038/s41893-021-00695-6 